\title{
IJCIT
}

(Indonesian Journal on Computer and Information Technology) Journal Homepage: http://ejournal.bsi.ac.id/ejurnal/index.php/ijcit

\section{Analisis Algoritma Klasifikasi Neural Network Untuk Diagnosis Penyakit Diabetes}

\author{
Jajang Jaya Purnama ${ }^{1}$, Sri Rahayu ${ }^{2,}$ Siti Nurdiani ${ }^{3}$, Tuti Haryanti ${ }^{4}$, Nissa Almira Mayangky ${ }^{5}$ \\ ${ }^{1}$ Teknologi Komputer, Univeristas Bina Sarana Informatika \\ Jakarta, Indonesia \\ Jajangja2412@bsi.ac.id \\ ${ }^{2,3,4,5}$ Sistem Informasi, STMIK Nusa Mandiri \\ Jakarta, Indonesia \\ srirahayu.rry@nusamandiri.ac.id ${ }^{2}$, siti.sxd@nusamandiri.ac.id ${ }^{3}$, tuti@nusamandiri.ac.id ${ }^{4}$, \\ nissa.nky@nusamandiri.ac.id ${ }^{5}$
}

\begin{abstract}
A B S T R A K
Diabetes merupakan penyakit yang sangat mematikan terbukti dari tahun ke tahun selalu ada yang meninggal dikarnakan pasien tersebut mengidap penyakit diabetes, banyak cara penangguhan sejak dini penyakit diabetes. Salah satunya dengan data mining klasifikasi algoritma neural network yang dapat digunakan untuk prediksi pasien mana yang terkena penyakit diabetes dan pasien mana yang tidak terkena diabetes dengan menggunakan parameter dan indikator yang ada, dan tools yang digunakan adalah tools rapid miner 9.0 yang mengahasilkan accuracy sebesar $=80.00 \%$ precision sebesar $=100.00$ $\%$ dan recall sebesar $=2.50 \%$ dengan AUC sebesar $=0.605 \%$ yang artinya klasifikasi dinyatakan cukup, dari hasil tersebut bisa dimbil kesimpulan bahwa penelitian ini bisa mencegah dan bisa diketahui sejak dini mana yang termasuk penyakit diabetes mana yang tidak mengidap penyakit diabetes, dan dari penelitian ini sangat diharapkan angka kematian bisa berkurang.

Katakunci: diabetes, klasifikasi, data mining, neural network.
\end{abstract}

\begin{abstract}
A B S T R A C T S
Diabetes is a very proven disease from year to year there are always people who die, many ways to postpone early diabetes. One of them is data mining neural network algorithm classification which can be used to predict which patients are affected by diabetes and which patients are not affected by diabetes by using existing parameters and indicators, and the tools used are rapid miner 9.0 tools that produce accuracy $=80.00 \%$ precision $=100.00 \%$ and recall of $=2.50 \%$ with AUC of $=0.605 \%$ which means the classification is declared sufficient, From these results it can be concluded that this study can prevent and can be known from the outset which of the diabetics do not have diabetes, and from this study it is expected that the mortality rate can be reduced.
\end{abstract}

Keywords: classification, data mining, diabetes, neural network. 


\section{PENDAHULUAN}

Diabetes mellitus adalah gangguan metabolisme yang secara genetik dan klinis termasuk heterogen dengan manifestasi berupa hilangnya toleransi karbohidrat, jika telah berkembang penuh secara klinis maka diabetes mellitus ditandai dengan hiperglikemia puasa postprandial, aterosklerosis dan penyakit vaskular mikroangiopati. (Fatimah, 2015).

Diabetes mellitus (DM) merupakan salah satu masalah kesehatan yang besar. Data dari studi global menunjukan bahwa jumlah penderita Diabetes Melitus pada tahun 2011 telah mencapai 366 juta orang. Jika tidak ada tindakan yang dilakukam, jumlah ini diperkirakan akan meningkat menjadi 552 juta pada tahun 2030. Diabetes mellitus telah menjadi penyebab dari 4,6 juta kematian. Selain itu pengeluaran biaya kesehatan untuk Diabetes Mellitus telah mencapai 465 miliar USD. International Diabetes Federation (IDF) memperkirakan bahwa sebanyak 183 juta orang tidak menyadari bahwa mereka mengidap DM. Sebesar $80 \%$ orang dengan DM tinggal di negara berpenghasilan rendah dan menengah. Pada tahun 2006, terdapat lebih dari 50 juta orang yang menderita DM di Asia Tenggara. Jumlah penderita DM terbesar berusia antara 40-59 tahun(Trisnawati \& Setyorogo, 2013).

Ada beberapa jenis Diabetes Mellitus yaitu Diabetes Mellitus Tipe I, Diabetes Mellitus Tipe II, Diabetes Mellitus Tipe Gestasional, dan Diabetes Mellitus Tipe Lainnya. Jenis Diabetes Mellitus yang paling banyak diderita adalah Diabetes Mellitus Tipe 2. Diabetes Mellitus Tipe 2 (DM Tipe 2) adalah penyakit gangguan metabolik yang di tandai oleh kenaikan gulah darah akibat penurunan sekresi insulin oleh sel beta pankreas dan atau ganguan fungsi insulin (resistensi insulin)(Trisnawati \& Setyorogo, 2013).

Diabetes melitus merupakan salah satu penyakit kronis yang dapat meningkatkan dengan cepat prevalensi komplikasi kronis pada lansia. Hal ini disebabkan kondisi hiperglikemia akibat ketiadaan absolut insulin atau penurunan relatif sensitivitas sel terhadap insulin, akan memicu munculnya penyakit tidak menular kronis lainnya, bahkan kematian penyandang diabetes melitus tidak jarang disebabkan oleh komplikasi.8,9 Klub Persadia Rumah Sakit Islam Jakarta Pondok Kopi Tahun 1998 _ 2005 menjelaskan bahwa komplikasi diabetes terbanyak adalah hipertensi dengan proporsi sekitar 54,2\%.(Rosyada \& Trihandini, 2010).

Prevalensi diabetes melitus yang terdiagnosis pada penduduk usia di atas 65 tahun menurut data Riskesdas tahun 2007 adalah 4,6\%. Diabetes melitus pada lansia seringkali tidak disadari karena gejala-gejala diabetes seperti sering haus, sering berkemih, dan penurunan berat badan tersamarkan akibat perubahan fisik alamiah lansia yang mengalami penurunan, sehingga diabetes yang tidak terdiagnosis ini akan terus berkembang menjadi komplikasi yang dapat berakibat fatal.11,12 Data di Rumah Sakit Umum Daerah (RSUD) dr. H. Abdul Moeloek Provinsi Lampung menunjukkan angka prevalensi diabetes melitus mencapai $35,5 \%$ dengan $76,2 \%$ mengalami komplikasi.13 Poli lansia puskesmas kecamatan Jatinegara juga menunjukkan angka prevalensi diabetes melitus yang tak jauh berbeda yaitu mencapai $29,3 \%$ pada lansia usia 60 _ 69 tahun dan 20,8\% pada lansia usia $\geq 70$ tahun.(Rosyada \& Trihandini, 2010).

Data mining adalah proses yang menggunakan teknik statistik, matematika, kecerdasan buatan, dan machine learning untuk mengekstraksi dan mengidentifikasi informasi yang bermanfaat dan pengetahuan yang terkait dari berbagai database besar. Istilah data mining memiliki hakikat sebagai disiplin ilmu yang tujuan utamanya adalah untuk menemukan, menggali, atau menambang pengetahuan dari data atau informasi yang kita miliki (Ridwan, Suyono, \& Sarosa, 2013).

NN Merupakan sebuah sistem pembelajaran terhadap penerimaan informasi yang memiliki kinerja layaknya sebah jaringan syaraf pada manusia. $N N$ diimplementasikan dengan menggunakan program komputer sehingga ma mpu menyelesaikan sejumlah proses perhitungan. Salah satu pengguna $N N$ adalah untuk pengenalan pola, sistem pengenalan pola merupakan komponen penting dalam proses peniruan cara kerja manusia (Nurmila \& Sugiharto, 2005).

Neural Network adalah prosesor yang terdistribusi paralel, terbuat dari unit-unit yang sederhana, dan memiliki kemampan untuk menyimpan pengetahuan yang diperoleh secara eksperimental dan siap pakai untuk berbagai tujuan 


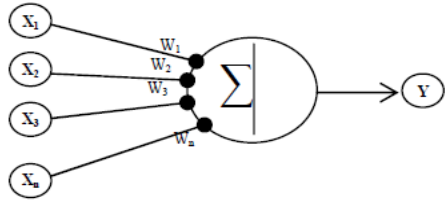

Gambar 1. Proses Komunikasi Antar Neuron

Pada gambar 1 diperlihatkan bahwa neural network terdiri atas satuan-satuan pemroses berupa neuron. $Y$ sebagai output menerima input dari neuron $\mathrm{X}_{1}, \mathrm{X}_{2}, \mathrm{X}_{3}, \ldots, \mathrm{X}_{\mathrm{n}}$ dengan bobot $W_{1}, W_{2}, W_{3}, \ldots ., W_{n}$. Hasil penjumlahan seluruh impuls neuron dibandingkan dengan nilai ambang tertentu melalui fungsi aktivasi $f$ setiap neuron. Fungsi aktivasi digunakan sebagai penentu keluaran suatu neuron.

Salah satu metode pelatihan dalam $N N$ adalah pelatihan terbimbing (supervised learning). Pada pelatihan terbimbing diperlukan sejumlah masukan dan target yang berfungsi untuk melatih jaringan hingga diperoleh bobot yang diinginkan.

Maka dalam penelitian ini penulis berfokus pada algoritma klaisifikasi machine learning yang akan digunakan adalah neural network yang bertujuan untuk memprediksi diagnosa penyakit diabetes yang ditujukan dengan besarnya akurasi setelah penulis melakukan penelitian menggunakan tools Rapid Miner.

\section{METODE PENELITIAN}

Penelitian ini dilakukan melalui beberapa tahapan, yaitu:

1) Menentukan Dataset

Penulis menggunakan data untuk penelitian ini adalah data diabetes yang didapat dari Machine Learning Repocitory $\mathrm{UCl}$ (Universitas California Invene) dengan alamat web : http://archive.ics.uci.edu/ml. Data yang dipakai sebanyak 220 sample.

2) Studi Literatur

Setelah penulis memperoleh dataset, kemudian mencari literatur guna menjadikan tolak ukur penelitian yang dilakukan.

3) Menentukan metode klasifikasi

Metode yang dipilih untuk permasalahan yang ada, penulis melihat dari bentuk dataset yang memiliki label (supervised) serta studi literatur yang dipelajari memiliki kecocokan sesuai yang sama, dengan demikian penulis memilih algoritma neural network karena merupakan salah satu algoritma klasifikasi prediksi yang akurasinya cukup tinggi.

4) Pengolahan Data Awal (Pre Processing)

Sebanyak 220 Data set dari data diabetes yang didapat dari UCI Repository akan ditransformasikan sesuai algoritma neural network dengan kriteria input data untuk rapid miner 9.0

5) Menerapkan Metode Learning dan Testing menggunakan Neural Network

Pembelajaran atau proses learning proses pertama dengan cara menghitung nilai prediksi data pada waktu terdahulu. Nilai diabetes diproses learning terlebih dahulu untuk mengetahui apakah dalam data ada nilai nominal atau tidak, apabila ada maka ubah nilai nominal menjadi numerik karena ada boost tidak dapat membaca nilai nominal. Pada tahap ini data hasil pengolahan antara training menggunakan Neural Network dan learning menggunakan Neural Network (backpropagation) setelah itu diuji untuk mengukur berapa akurasi trend dari prediksi.

6) Menerapkan Metode Evaluasi dan Validasi Hasil

Proses evaluasi dan juga pengamatan hasil kerja Neural Network pada Rapid Miner. Validasi dilakukan untuk melakukan pengukuran hasil prediksi.

a. Cross Validation

Cross validation adalah pengujian standar yang dilakukan untuk memprediksi error rate. Data training dibagi secara random ke dalam beberapa bagian dengan perbandingan yang sama kemudian error rate dihitung bagian demi bagian, selanjutnya hitung rata-rata seluruh error rate untuk mendapatkan error rate secara keseluruhan (Kepemilikan \& Bemotor, 2013)

b. Pengukran menggunakan ROC Curve Hasil perhitungan divisualisasikan dengan kurva ROC. Kurva ROC pada gambar mengekspresikan confusion matrix dari Gambar 2. Garis horizontal adalah false positives dan garis vertikal true positives. Terlihat pada gambar nilai AUC sebesar 0.984 .

Untuk klasifikasi data mining, nilai AUC dapat dibagi menjadi beberapa kelompok.

a. $0.90-1.00=$ klasifikasi sangat baik

b. $0.80-0.90=$ klasifikasi baik

c. $0.70-0.80=$ klasifikasi cukup

d. 0.60-0.70 = klasifikasi buruk

e. 0.50-0.60 = klasifikasi salah

(Kepemilikan \& Bemotor, 2013) 


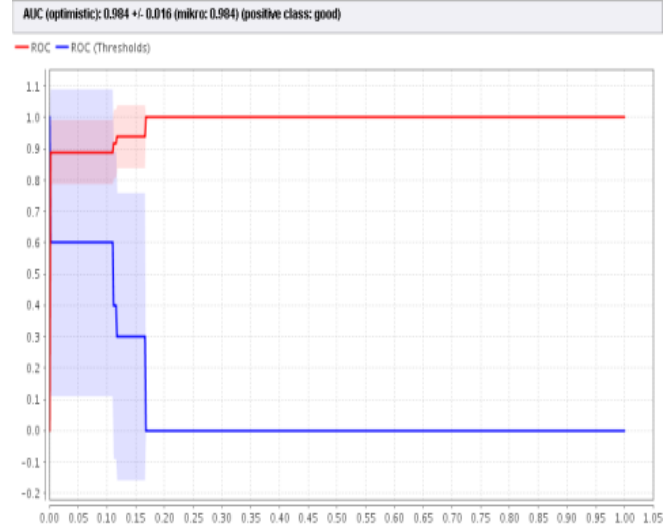

Sumber (Kepemilikan \& Bemotor, 2013)

Gambar 2. Kurva ROC Metode KNN

c. Pengukuran Confusion Matrix

Confusion matrix merupakan sebuah tabel yang terdiri dari atas banyaknya baris data uji yang diprediksi benar dan tidak benar oleh model klasifikasi, tabel ini diperlukan untuk menentukan kinerja suatu model klasifikasi (Wijayanto, n.d.)

Tabel 1. Tabel Confusion Matrix

\begin{tabular}{cccc}
\hline & & \multicolumn{2}{c}{ Predicted Class } \\
\hline \multirow{2}{*}{ Actual } & Class & Class $=1$ & Class $=0$ \\
\cline { 2 - 4 } Class & Class $=1$ & F 11 & F 10 \\
& Class $=0$ & F 01 & F 00 \\
\hline
\end{tabular}

Perhitngan akurasi dengan menggunakan tabel confusion matrix adalah sebagai berikut :

Akurasi $=\frac{F 11+F 00}{F 11+F 10+F 01+F 00}$

7) Menarik Kesimpulan

Setelah penulis selesai mengelola dataset dan didapat hasilnya secara kuantitatif, maka penulis dapat menarik kesimpulan apakah dataset tersebeut dengan klasifikasi 1 berhasil dan 0 untuk gagal mendapatkan akurasi yang tinggi atau tidak, sehingga keberhasilan metode pengobatan.

\section{PEMBAHASAN}

Proses training, learning, dan testing menggunakan model neural network dengan dataset sebanyak 220 data sebagai berikut:

1) Membuka aplikasi tools rapid miner, cari read excel di operator untuk memasukan dataset

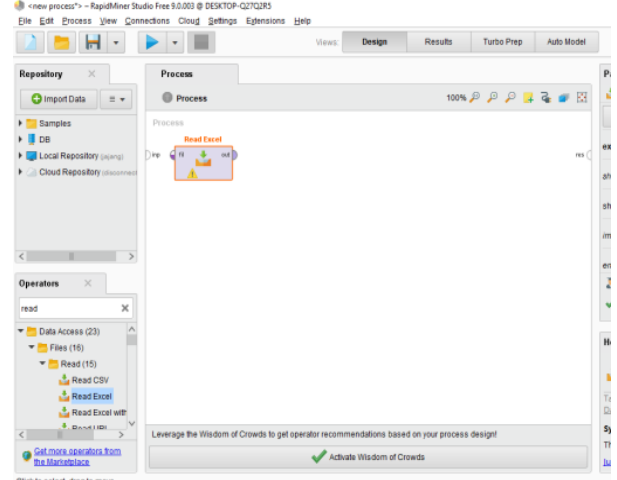

Gambar 3. Input Operator Read Excel

2) Memasukan data primer ke dalam read excel dengan atributnya adalah encounter_id, patient_nbr, race, gender, age, admission_type_id, discharge_disposition_id,

admission_source_id, time_in_hospital, medical_speciality, num_lab_procedures, num_procedures, num_medications, number_outpatient, number_emergency, number_inpatient, diag_1, diag_2, diag_3, diabetesMed,

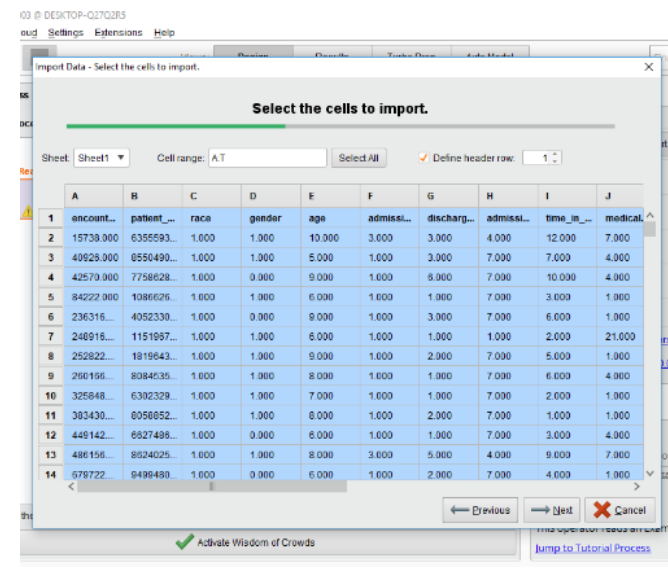

Gambar 4. Input Dataset

3) Setelah memasukan dataset, tool akan mengetahui format dari setiap kolomnya.

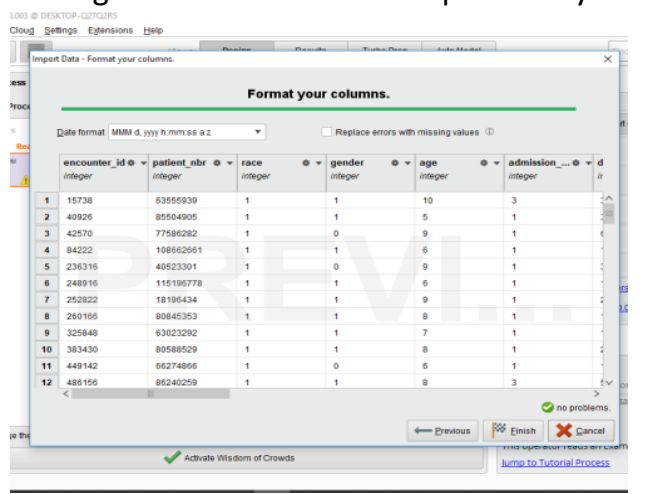

Gambar 5. Format dataset 
4) Di kolom edit parameter data set meta data information kita bisa mengedit atribut yang kita udah masukan.

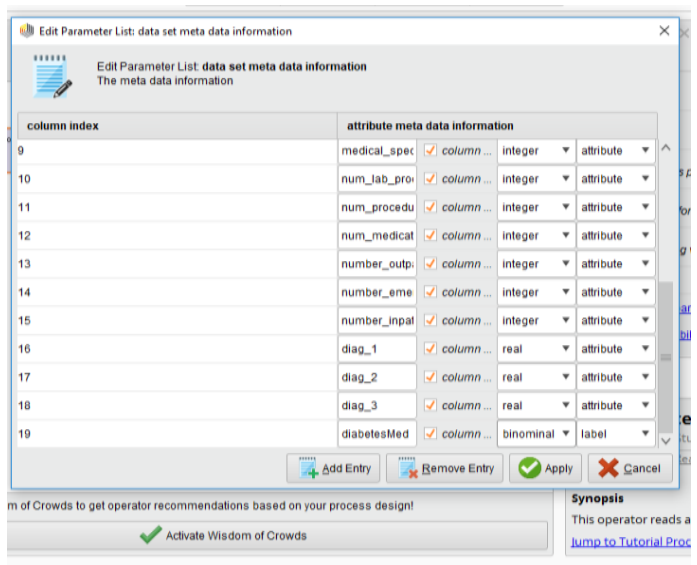

Gambar 6. Mengatur Atribut

5) Proses insert dan atur validation dengan nmber of folds 10 .

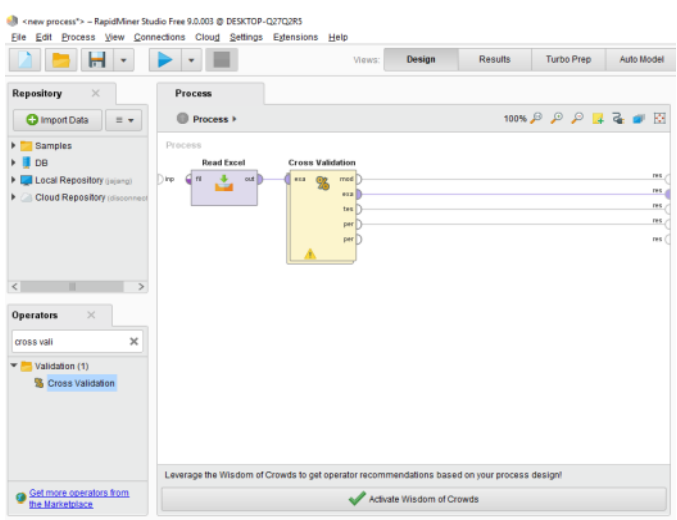

Gambar 7. Proses Mengatur Atribut

6) Proses berikutnya adalah proses insert model yang akan di training, pada proses training kali ini dengan memasukan model algoritma neural network dengan menggunakan data set sebanyak 220 .

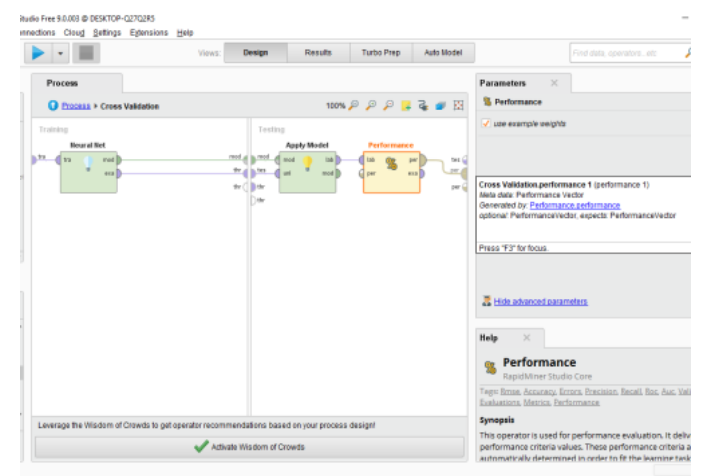

Gambar 8. Insert dan Atur Validation
7) Proses terakhir adalah proses testing dengan cara insert apply dan performance dengan main criterion accuracy dan AUC.

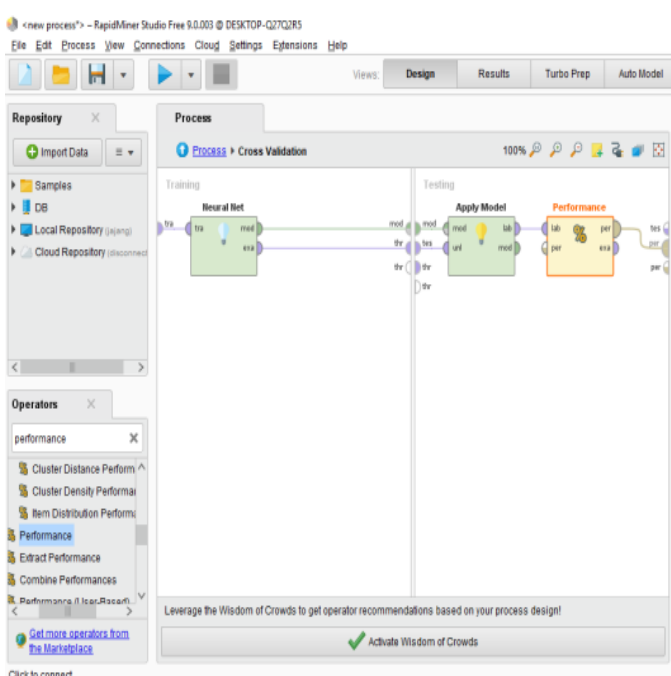

Gambar 9. Proses Insert Model NN Yang Akan di Training

8) Hasil testing bisa diperoleh dengan cara insert apply model dan performance dengan main criterion accuracy dan AUC.

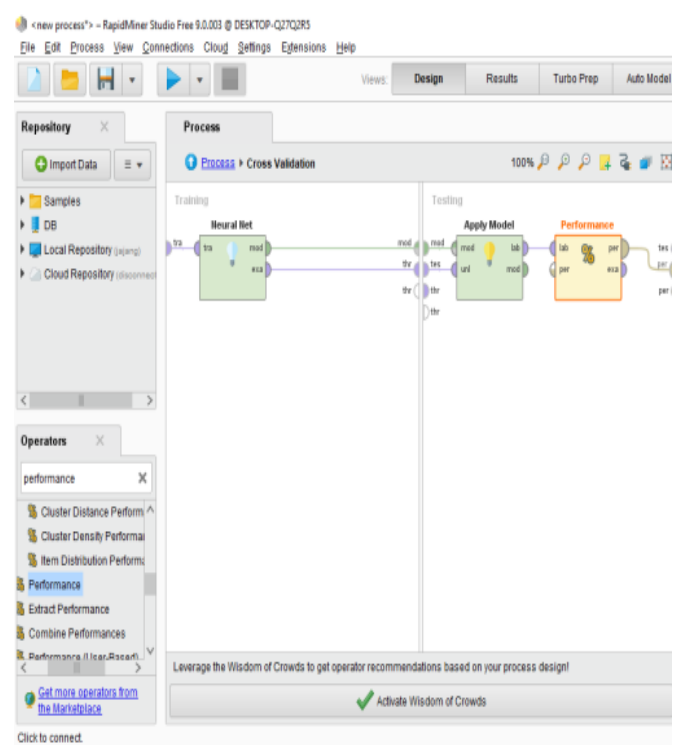

Gambar 10. Proses Testing Dengan Cara Insert Apply Model dan Performance

9) Hasil testing menunjukan performance accuracy yang dihasilkan menggunakan algoritma Neural Network sebesar $80.00 \%$ dan nilai AUC sebesar 0.605 .

10) Setelah proses testing dengan apply model hasil pengujian Neural Network 


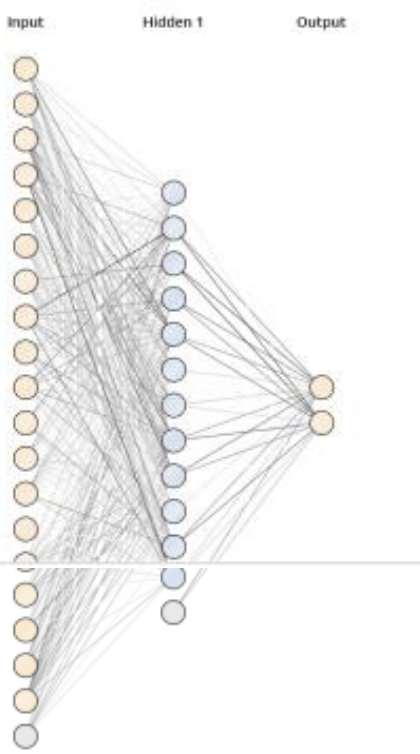

Gambar 11. Model Hasil Pengujian Neural Network

\section{Evaluasi dan Validasi}

Penelitian ini bertujuan untuk menguji akurasi dari analisa penyakit diabetes menggunakan algoritma neural network data yang dianalisa adalah data diabetes yang diperoleh data dari UCl Repository. Dengan bantuan rapid miner ternyata dapat diketahui algoritma neural network mempunyai akurasi yang tinggi.

\section{a. Uji Roc Curva}

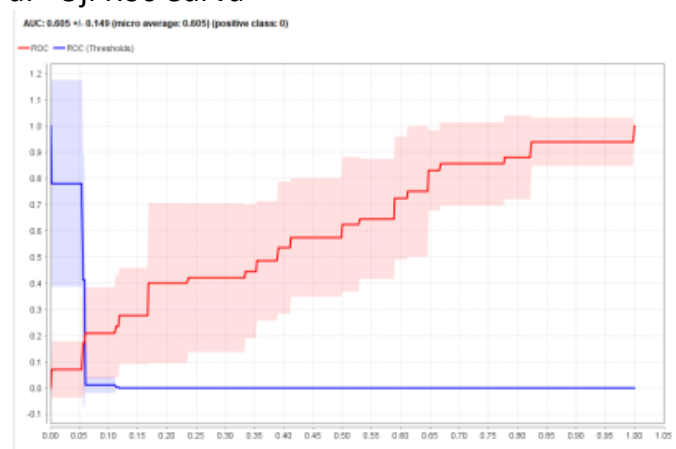

Gambar 12. AUC Neural Network

Menggambarkan grafik under curve (AUC) hasil validasi Neural Network dengan hasil AUC sebesar 0,605. Ini menunjukan nilai dibawah curve sebesar 0,605.

b. Menggambarkan grafik area under curve (AUC) optimistic hasil validasi Neural Network dengan nilai yang tertera dalam gambar sebesar $=0,605$.

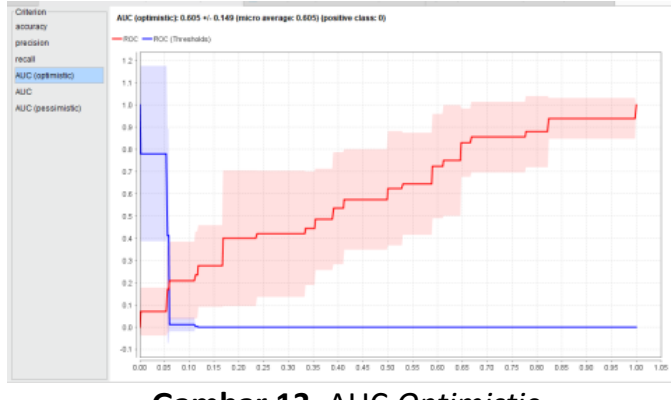

Gambar 13. AUC Optimistic

c. Menggambarkan grafik area under curve (AUC) pesimistic hasil validasi Neural Network sebesar $=0,605$.

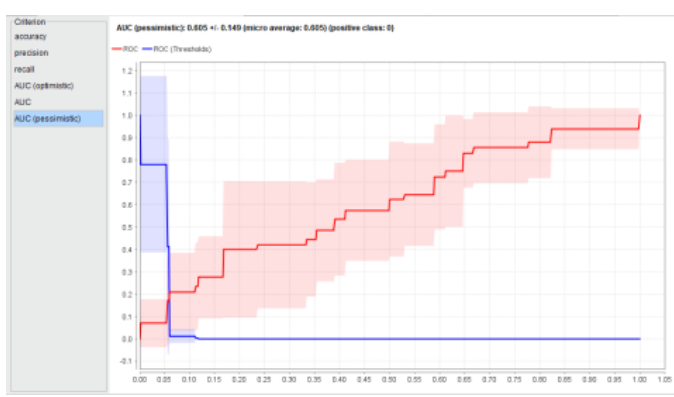

Gambar 14. AUC Pesimistic

\section{d. Uji Confusion Matrix}

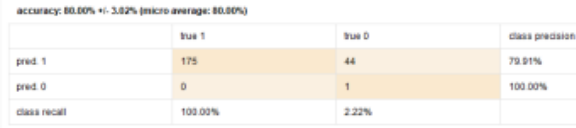

Gambar 15. Uji Confusion Matrix

Berdasarkan gambar diatas dapat ketahui bahwa hasil accuracy dari metode klasifikasi Neural Network sebesar 80.00 \% ini menunjukan bahwa hasil akurasi yang diperoleh termasuk kedalam kategori baik.

e. Menggambarkan precision dari metode klasifikasi Neural Network sebesar $100.00 \%$ (positive class: 0) ini menunjukan bahwa hasil akurasi yang diperoleh masuk dalam kategori sangat baik.

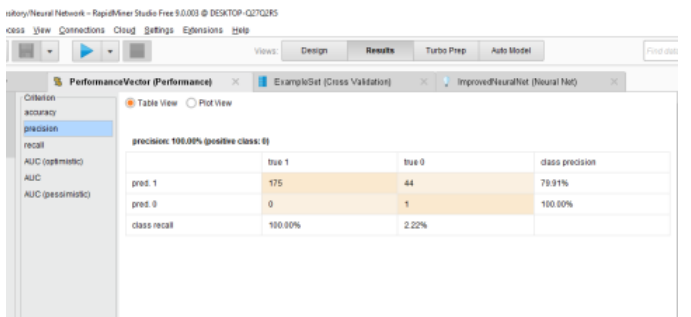

Gambar 16. Precission Klasifikasi NN 
f. Menggambarkan hasil recall dari metode klasifikasi Neural Network sebesar $=2.50 \%$

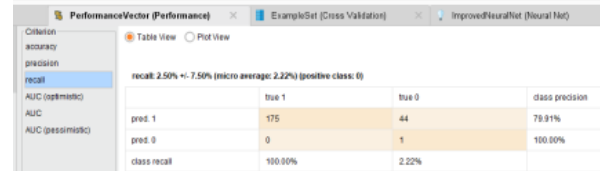

Gambar 17. Recall Klasifikasi Neural Network

g. Memberikan informasi secara keseluruhan tentang hasil dan validasi dengan metode klasifikasi Neural Network yang terdiri dari hasil accuracy,, precision, recall dan juga nilai AUC dan hasil lainnya seperti performance vektor (confusion matrix).

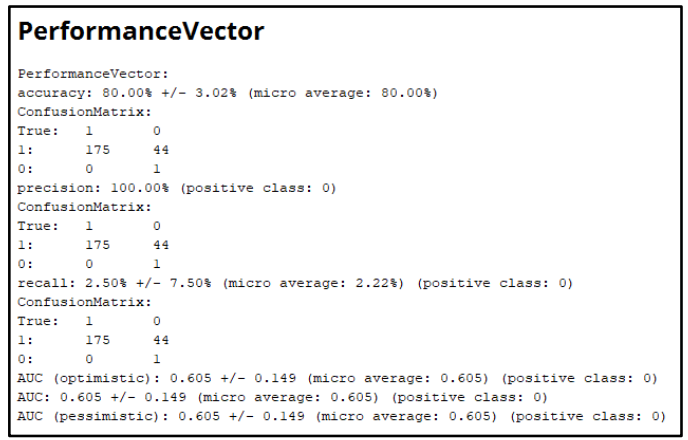

Gambar 18. Performance Vektor Neural Network

\section{KESIMPULAN}

Berdasarkan penelitian yang dilakukan oleh penulis menggunakan tools rapid 9.0 terhadap dataset diabetes yang didapat dari $\mathrm{UCl}$ repository yang diuji dengan metode Neural Network menghasilkan nilai accuracy $=80.00 \%$ , precission $=100.00 \%$ dan recall $=2.50 \%$ dengan AUC sebesar $=0.605$ yang mennjukan bahwa hasil klasifikasinya cukup, sehingga dari dataset tersebut dapat diprediksi mana saja yang mengidap penyakit diabetes dan mana yang bukan, sehingga dapat diprediksi dan menjadi tolak ukur diagnosis sehingga dapat dideteksi lebih dini.

\section{REFERENSI}

Fatimah, R. N. (2015). DIABETES MELITUS TIPE 2. J MAJORITY, 4, 93-101.

Kepemilikan, K., \& Bemotor, K. (2013). Penerapan algoritma k-nearest neighbor untuk penentuan resiko kredit kepemilikan kendaraan bemotor. Jurnal Penelitian IImu Komputer, System Embedded \& Logic, 1(1), 65-76.

Nurmila, N., \& Sugiharto, A. (2005). Algoritma back propagation neural network untuk pengenalan pola karakter huruf jawa. Masyarakat Informatika, 1, 1-10.

Ridwan, M., Suyono, H., \& Sarosa, M. (2013). Penerapan Data Mining Untuk Evaluasi Kinerja Akademik Mahasiswa Menggunakan Algoritma Naive Bayes Classifier. EECCIS, 7(1), 59-64.

Rosyada, A., \& Trihandini, I. (2010). Determinan Komplikasi Kronik Diabetes Melitus pada Lanjut Usia Determinan of Diabetes Mellitus Chronic Complications on Elderly. Jurnal Kesehatan Masyarakat Nasional, 395-401.

Trisnawati, S. K., \& Setyorogo, S. (2013). Faktor Risiko Kejadian Diabetes Melitus Tipe II Di Puskesmas Kecamatan Cengkareng Jakarta Barat Tahun 2012. Jurnal IImiah Kesehatan, 5(1), 6-11.

Wijayanto, H. (n.d.). KLASIFIKASI BATIK MENGGUNAKAN METODE K-NEAREST NEIGHBOUR BERDASARKAN GRAY LEVEL CO-OCCURRENCE MATRICES ( GLCM ), (5). 